\section{Progress in automated extraction and purification of in situ ${ }^{14} \mathrm{C}$ from quartz: Results from \\ 8 the Purdue in situ ${ }^{14} \mathrm{C}$ laboratory}

10 Nathaniel Lifton ${ }^{1,2, *}$, Brent Goehring ${ }^{1, * *}$, Jim Wilson $^{3}$, Thomas Kubley $^{2}$, Marc Caffee $^{2}$

121 Department of Earth, Atmospheric, and Planetary Sciences, Purdue University, 550 Stadium

13 Mall Drive, West Lafayette, Indiana, 47907, USA. E-mail: nlifton@ purdue.edu

142 Department of Physics and Astronomy and Purdue Rare Isotope Measurement Laboratory

15 (PRIME Lab), Purdue University, 525 Northwestern Avenue, West Lafayette, Indiana, 16 47907, USA.

173 Aeon Laboratories, LLC, 5835 North Genematas Drive, Tucson, Arizona, 85704, USA. E18 mail: jim.wilson@aeonlaboratories.com

20 * Corresponding Author

$21 * * \quad$ Now at: Department of Earth and Environmental Sciences, Tulane University, 6823 St

22 Charles Avenue, New Orleans, Louisiana, 70118, USA. E-mail: bgoehrin@ tulane.edu

\title{
24 Abstract
}

25 Current extraction methods for in situ ${ }^{14} \mathrm{C}$ from quartz [e.g., 1, 2, 3] are time-consuming and 26 repetitive, making them an attractive target for automation. We report on the status of in situ ${ }^{14} \mathrm{C}$

27 extraction and purification systems originally automated at the University of Arizona that have

28 now been reconstructed and upgraded at the Purdue Rare Isotope Measurement Laboratory

29 (PRIME Lab). The Purdue in situ ${ }^{14} \mathrm{C}$ laboratory builds on the flow-through extraction system

30 design of Pigati et al. [2], automating most of the procedure by retrofitting existing valves with

31 external servo-controlled actuators, regulating the pressure of research purity $\mathrm{O}_{2}$ inside the

32 furnace tube via a PID-based pressure controller in concert with an inlet mass flow controller,

33 and installing an automated liquid $\mathrm{N}_{2}$ distribution system, all driven by LabView ${ }^{\circledR}$ software. A 
34 separate system for cryogenic $\mathrm{CO}_{2}$ purification, dilution, and splitting is also fully

35 automated, ensuring a highly repeatable process regardless of the operator. We present results

36 from procedural blanks and an intercomparison material (CRONUS-A), as well as results of

37 experiments to increase the amount of material used in extraction, from the standard $5 \mathrm{~g}$ to $10 \mathrm{~g}$

38 or above. Results thus far are quite promising with procedural blanks comparable to previous

39 work and significant improvements in reproducibility for CRONUS-A measurements. The latter

40 analyses also demonstrate the feasibility of quantitative extraction of in situ ${ }^{14} \mathrm{C}$ from sample

41 masses up to $10 \mathrm{~g}$. Our lab is now analyzing unknowns routinely, but lowering overall blank

42 levels is the focus of ongoing research.

43 Keywords: carbon-14; cosmogenic; carbon isotopes; automation techniques 


\section{0 - Introduction}

45 Extracting in situ cosmogenic ${ }^{14} \mathrm{C}$ (in situ ${ }^{14} \mathrm{C}$ ) from quartz is a challenging endeavor: minute

46 quantities of ${ }^{14} \mathrm{C}$ must be extracted and purified from quartz samples while maintaining

47 scrupulous isolation from ubiquitous atmospheric/organic ${ }^{14} \mathrm{C}$. Building on procedures developed

48 for extraction of in situ ${ }^{14} \mathrm{C}$ and stable carbon species from meteorites and basaltic glasses [e.g., 4,

49 5-7], Lifton et al. [1] presented techniques for quantitative extraction of in situ ${ }^{14} \mathrm{C}$ from quartz

50 using degassed lithium metaborate $\left(\mathrm{LiBO}_{2}\right)$ as a flux to dissolve quartz at $1100^{\circ} \mathrm{C}$ in a stream of

51 Research Purity $\mathrm{O}_{2}(99.999 \%)$, oxidizing all C-species to $\mathrm{CO}_{2}$. Although workable, these

52 techniques are quite labor-intensive and time-consuming, requiring up to ca. 20 man-hours to

53 process a quartz sample into a graphite target for analysis by accelerator mass spectrometry

54 (AMS). Alternate methods published to date that involve high-temperature extraction of ${ }^{14} \mathrm{C}$ from

55 quartz are similarly time-consuming [e.g., 2, 3, 8, 9]. Automating these procedures would make

56 lab personnel more efficient and increase analytical reliability, offering the potential for

57 significantly increasing lab throughput and helping to raise the profile of in $\operatorname{situ}{ }^{14} \mathrm{C}$ as a tool for 58 surficial process studies.

59 After significant effort, the in situ cosmogenic ${ }^{14} \mathrm{C}$ laboratory at the Purdue Rare Isotope

60 Measurement Laboratory (PRIME Lab) is now operational, with fully automated procedures for

61 extraction and $\mathrm{CO}_{2}$ purification. Below we describe the design and implementation of these

62 automated systems, and present some early results.

\section{$63 \quad 2.0$ - System Description}

64 The Purdue in situ ${ }^{14} \mathrm{C}$ laboratory has two identical high-temperature extraction systems and 65 one $\mathrm{CO}_{2}$ purification system, based on the flow-through design and procedures described in 
Lifton et al. $\quad$ Automated extraction and purification of in situ ${ }^{14} \mathrm{C}$

66 Pigati et al. [2] which were modified from the original recirculating in situ ${ }^{14} \mathrm{C}$ system of

67 Lifton et al [1] (Figs. 1 and 2a). Each extraction system consists of three major parts: (1) a tube

68 furnace capable of reaching $>1200^{\circ} \mathrm{C}$, fitted with a dedicated $5 \mathrm{~cm}$ o.d. mullite tube; (2) a U-

69 shaped secondary combustion furnace packed with $2 \mathrm{~mm}$ diameter fused quartz beads set at ca.

$70 \quad 1000^{\circ} \mathrm{C}$; and (3) a single cryogenic coil trap (Fig. 1). Each is maintained at high vacuum with

71 turbo pumps backed by dry scroll pumps. The mullite tube has borosilicate glass polished socket

72 joints sealed to each end with o-ring ball joint end caps to enable easy access. A $12 \mathrm{~mm}$ glass

73 nipple extends at right angles from the glass sections on each side of the tube to connect the tube

74 to the vacuum system via Cajon ${ }^{\circledR}$ fittings. Glass fritted tubes (coarse porosity) are installed

75 between the nipples and the rest of the vacuum system to guard against particulate contamination.

76 These frits also slow the movement of oxygen through the mullite tube, minimizing the

77 possibility of disturbing the sample during extraction. Oxygen flow is controlled with an MKS

78 Instruments $1479 \mathrm{~A}$ mass flow controller with a range of 0-20 standard cubic centimeters

$79(\mathrm{~mL}) / \mathrm{minute}(\mathrm{sccm})$, and tube pressure is maintained between 0-100 torr via an MKS Instruments

$80640 \mathrm{~B}$ pressure controller.

81 We follow a two-day extraction process similar to that of Pigati et al. [2]. We summarize the

82 process here. The first day is dedicated to 1) flame-cleaning carbon-bearing contaminants from

83 the quartz sleeve that lines the furnace tube to prevent condensation of $\mathrm{LiBO}_{2}$ on the tube itself,

84 and 2) fusing and degassing $20 \mathrm{~g}$ of $\mathrm{LiBO}_{2}$ in a $50 \mathrm{~mL} \mathrm{Al}_{2} \mathrm{O}_{3}$ sample boat. After cooling

85 overnight, the boat is retrieved from the furnace and placed in a laminar flow hood using flame-

86 cleaned quartz implements. The sample is loaded on top of the fused $\mathrm{LiBO}_{2}$, and the boat is

87 returned to the furnace tube. After evacuating the extraction system with the furnace at $180^{\circ} \mathrm{C}$ for 
Lifton et al. Automated extraction and purification of in situ ${ }^{14} \mathrm{C}$

8890 minutes, the boat is heated to $500^{\circ} \mathrm{C}$ in a stream of Research Purity $\mathrm{O}_{2}$ at ca. 50 torr for 1

89 hour to remove atmospheric contaminants, and then oxidized in $\mathrm{O}_{2}$ at $1100^{\circ} \mathrm{C}$ for 3 hours.

90 Approximately 4-6 tube volumes of Research Purity $\mathrm{O}_{2}$ are bled slowly through the furnace

91 tube at approximately 50 torr pressure during the high-temperature extraction step, carrying

92 evolved sample gases through the secondary combustion furnace before condensable gases are

93 collected in the coil trap. These gases are then transferred to a borosilcate glass breakseal for

94 loading into the separate purification system to isolate the evolved $\mathrm{CO}_{2}$ component.

95 The purification system removes water, halides, nitrogen and sulfur species using a

96 combination of cryogenic separation with variable temperature traps and a $\mathrm{Cu}$ mesh/Ag wool

97 furnace held at ca. $475^{\circ} \mathrm{C}$. The amount of purified $\mathrm{CO}_{2}$ is then measured in a known volume,

98 diluted with ${ }^{14} \mathrm{C}$-free $\mathrm{CO}_{2}$ to approximately $0.4 \mathrm{mg} \mathrm{C}$-equivalent. A small aliquot of the diluted

99 mixture is split into a $12 \mathrm{~mL}$ Exetainer ${ }^{\circledR}$ for offline $\delta^{13} \mathrm{C}$ measurement at the Purdue Stable

100 Isotope Facility (PSI), and the remainder transferred to a second breakseal for transfer to the

101 graphitization system. Graphitization system design and procedures are based on those of Santos

102 et al. [10, 11], using $\mathrm{H}_{2}$ reduction of $\mathrm{CO}_{2}$ over an Fe catalyst at $580^{\circ} \mathrm{C}$, with $\mathrm{Mg}\left(\mathrm{ClO}_{4}\right)_{2}$ as a water

103 trap. The graphitization system comprises 8 reactors: 6 for low-level analyses and 2 with larger

104 volumes intended for graphitization of AMS standards (Fig. 2b).

105

\section{1 - System Automation}

106 The original implemention of the extraction system at the University of Arizona $[1,2]$

107 required manual operation of all valve and liquid nitrogen procedures. The repetitive and time-

108 consuming nature of the processes makes automation attractive; automating multiple extraction

109 systems would maximize sample throughput. At Arizona existing systems were retrofitted for 
Lifton et al. $\quad$ Automated extraction and purification of in situ ${ }^{14} \mathrm{C}$

110 automation rather than building new systems. This required custom design and

111 implementation of equipment to automate three key aspects of the systems: valve operation,

112 temperature control, and liquid nitrogen (LN) transfer. Each system is operated using LabView ${ }^{\circledR}$

113 software in a Windows 7 environment, linked to a dedicated enclosure housing custom-designed

114 control electronics (Fig. 2c) that include data acquisition and digital input/output modules.

115 Considerable effort has been devoted to optimizing design reliability and efficiency of each 116 system.

\section{$117 \quad 2.1 .1-$ Valve actuators}

118 A variety of valves facilitate the movement of gases through the system. Most of the valves 119 are glass valves with Viton ${ }^{\circledR}$ o-ring seals (Kimble-Chase HI-VAC with glass plug); these are 120 supplemented by Swagelok SS-4BK bellows-sealed stainless steel valves. Edwards Vacuum 121 backing-roughing valves are used to switch between high- and low-vacuum states. Given the 122 range of valve types and sizes, special purpose electromechanical actuators were designed to 123 open and close the valves via commands from the control system (Fig. $2 \mathrm{~d}$ and e). Each actuator 124 uses a servo-loop-controlled gear-motor to translate electronic speed and direction commands 125 into mechanical motion. Detector switches send position information back to the control system. 126 Gate valves above the turbo pump inlets are operated pneumatically.

127 A mechanism to crack breakseals in the purification process was also designed and

128 implemented. This is accomplished by first scoring the breakseal circumference at a

129 predetermined distance from the bottom end (to ensure proper placement in the tube cracker).

130 The breakseal is then cleaned with ethanol-moistened lint-free wipes and inserted into the bottom 131 of the tube cracker mechanism. The tube cracker consists of a Swagelok ${ }^{\circledR} 3 / 8$ " (ca. $\left.0.9 \mathrm{~cm}\right)$ o.d. x 13212 " (ca. $30.5 \mathrm{~cm}$ ) long stainless steel flexible tube with Cajon ${ }^{\circledR}$ fittings on the ends, and a glass 
Lifton et al. $\quad$ Automated extraction and purification of in situ ${ }^{14} \mathrm{C}$

133 plug in the bottom fitting. The flexible tube is held securely on either side of the scored

134 portion of the breakseal via bushings in holes bored through two plastic blocks - the upper block

135 is fixed to the servo motor housing and the lower one is attached to the motor spindle. When

136 activated the lower block rotates approximately $60^{\circ}$ and cracks the breakseal at the scored

137 location, then returns to its original position.

$138 \quad 2.1 .2$ - Temperature control and monitoring

139 Two main aspects of temperature control are automated. For the extraction systems, the main 140 tube furnace is interfaced to the control electronics by an RS-232 via USB connection, and

141 operated via software. The control electronics for the purification system operate the variable

142 temperature traps (VTTs), which allow the separation of gas species based on characteristic phase

143 transition temperatures. Each VTT contains a cold finger surrounded by a heater coil and

144 enclosed within a sealed tube filled with helium. A type T thermocouple is attached to the cold

145 finger. With the helium-filled tube submerged in liquid nitrogen, power to the heater coil is then

146 controlled using the temperature feedback from the thermocouple. The cold finger temperature is

147 maintained at any desired temperature from -196 to $-100^{\circ} \mathrm{C}$.

$148 \quad 2.1 .3-$ Liquid $\mathrm{N}_{2}$ transfer

149 Transferring LN to and from needed locations in each system is the most difficult aspect of

150 the procedures to automate; condensation being a constant concern. LN is transferred from a

151 pressurized $200 \mathrm{~L}$ supply dewar through insulated Teflon tubing to fill dewars on various cold

152 traps or VTTs. This is accomplished via a manifold containing a series of solenoid valves that

153 which are rated for cryogenic service. The amount of LN in the supply dewar is monitored by

154 weight as measured with a $300 \mathrm{~kg}$ load cell assembly. Filling and emptying of individual dewars 
Lifton et al. $\quad$ Automated extraction and purification of in situ ${ }^{14} \mathrm{C}$

155 is controlled using LN level sensors comprising three $1 \mathrm{M} \Omega$ carbon-composition resistors in

156 series, positioned with resistors at empty, nominal, and full levels within each dewar. Certain

157 cold traps need to be alternately filled, emptied, and warmed. Dewars stationed on those traps are

158 emptied using a small shop vacuum cleaner via a drain manifold fitted with cryogenic solenoid

159 valves. Cold traps are warmed gently using heat guns capable of temperatures $<100^{\circ} \mathrm{C}$.

$160 \quad 2.2-$ PRIME Lab

161 Although these automated systems were operational at Arizona in late 2009, they were

162 disassembled and moved with Lifton to PRIME Lab in 2010. A new laboratory layout there

163 required reconfiguration of the systems. In addition, several design changes were made to

164 simplify the procedures and increase overall robustness of the automated operation. These

165 included adding the pressure controller to each extraction system and removing the central two of

166 four original VTTs from the purification system. By modifying our procedures slightly we were

167 able to achieve similar levels of $\mathrm{CO}_{2}$ purity with only two VTTs, as evidenced by the agreement

168 of our results for the CRONUS-A intercomparison material with those of previous analyses [12]

169 (Section 3.3). In addition, experiments were conducted using slightly positive He pressure when

170 opening the extraction system furnace tubes to prevent atmospheric incursion. All systems are

171 now operational at PRIME Lab.

\section{$172 \quad 3.0$ - System Operation and Initial Results}

173 The automation of the PRIME Lab in situ ${ }^{14} \mathrm{C}$ systems has enabled extremely consistent

174 process conditions within each system from run to run. For example, the amount of $\mathrm{O}_{2}$ bled

175 through each extraction system during the $1100^{\circ} \mathrm{C}$ step varies only by $<0.2 \%$ between runs. 
Lifton et al. $\quad$ Automated extraction and purification of in situ ${ }^{14} \mathrm{C}$

176 Similar process reproducibility is observed in the other steps of extraction and purification

177 as well.

178 Automation has allowed for significant reduction in overall process times. The $\mathrm{LiBO}_{2}$

179 pretreatment on the first process day now only takes ca. 3.5 hours, compared to ca. 5 hours

180 previously. Similarly, the sample extraction on the second day now takes ca. 6-7 hours, compared

181 to ca. 8 hours before automation. Sample purification takes ca. 3.5 hours, comparable to before

182 automation, but can now run unattended, and the $\mathrm{H}_{2}$-reduction graphitization is significantly

183 faster than the previous $\mathrm{Zn}$ reduction process (Section 3.1).

184 Our initial characterization of these systems comprised three series of tests: graphitization 185 blanks, process blanks, and analyses of the CRONUS-A intercomparison material [12]. We report

186 on each of these below. Results are reported in terms of ${ }^{14} \mathrm{C} / \mathrm{C}_{\text {total }}$ following Hippe and Lifton

187 [13], which for in situ ${ }^{14} \mathrm{C}$ is a more appropriate method of data reduction and reporting than 188 traditional fraction modern $\left(\mathrm{F}_{\mathrm{m}}\right)$ or percent modern carbon $(\mathrm{pMC})$. All uncertainties are reported 189 as $1 \sigma$.

$190 \quad 3.1-$ Graphitization blanks

191 Our new graphitization systems rely on $\mathrm{H}_{2}$ reduction of $\mathrm{CO}_{2}$ over an Fe catalyst [e.g., 10, 11]

192 instead of $\mathrm{Zn}$ reduction [14] which is used at the University of Arizona. The advantage of $\mathrm{H}_{2}$

193 reduction over $\mathrm{Zn}$ is primarily speed; graphitization typically is completed in $<2$ hours with $\mathrm{H}_{2}$

194 instead of ca. 18-20 hours for $\mathrm{Zn}$ in our Arizona systems. We also use a constant mass of Fe for

195 all samples $(3.0 \pm 0.1 \mathrm{mg})$ regardless of carbon mass, in contrast to a $\mathrm{Fe}: \mathrm{C}$ ratio of ca. $2.0 \mathrm{in}$

196 Arizona. 
Lifton et al. $\quad$ Automated extraction and purification of in situ ${ }^{14} \mathrm{C}$

197 Previous experience with graphitization suggests an inverse dependence of the

198 measured ${ }^{14} \mathrm{C} /{ }^{13} \mathrm{C}$ ratio (or $\mathrm{F}_{\mathrm{m}}$ ) on the mass of carbon in the sample for both $\mathrm{Zn}$ and $\mathrm{H}_{2}$-based

199 systems [e.g., 1, 15, 16]. Given the procedural differences between previous and current systems,

200 we conducted experiments to determine the mass dependence of the blank associated with our 201 graphitization process. Aliquots of the ${ }^{14} \mathrm{C}$-free $\mathrm{CO}_{2}$ we use for dilution were prepared in sizes

202 ranging from 0.14 to $2.0 \mathrm{mg} \mathrm{C}$. Results follow the expected $1 / \mathrm{M}$ dependence; the blank ${ }^{14} \mathrm{C} / \mathrm{C}_{\text {total }}$

203 [corresponding to " $\mathrm{f}$ " in Eq. 25 of 15], associated with graphitization of the typical diluted sample 204 size of ca. $0.4 \mathrm{mg} \mathrm{C}$ is ca. $3 \times 10^{-15}$ (Table 1; Fig. 3).

205 $\underline{3.2-\text { Process blanks }}$

206 Procedural blanks were conducted on initial startup of each extraction system and

207 subsequently interspersed with CRONUS-A and unknown samples. Each blank analysis

208 consisted of the full set of procedures normally utilized for extraction and purification of a quartz

209 sample, but without adding any quartz. The initial set of extractions using the first extraction

210 system (Line 1) involved opening the furnace tube to air during sample insertion and removal,

211 following previous procedures $[1,2,9,17]$, while a second set maintained a slow flow of

212 Research Purity He (99.9999\%) through the furnace tube at slightly above atmospheric pressure

213 while open to prevent atmospheric incursion (Table 2, Fig. 4). An initial set of blanks on the

214 second extraction system (Line 2) used only the He flow procedures.

215 Results from the initial set of process blanks on Line 1 yielded a mean blank of $(1.64 \pm 0.45)$

$216 \times 10^{5}{ }^{14} \mathrm{C}$ atoms (n=7) (Fig. 4). Six of the seven initial blanks were within $1 \sigma$ of the mean; one

217 (PISC-35) was within $2 \sigma$. The $>27 \%$ coefficient of variation (COV - mean divided by standard

218 deviation) indicates significant room for improvement. The source of the variability is not 
Lifton et al. $\quad$ Automated extraction and purification of in situ ${ }^{14} \mathrm{C}$

219 obvious from procedural considerations. We attempted to mitigate this variability by

220 slowly back-flushing the furnace tube with Research Purity He during insertion and removal of

221 the sample boat and quartz sleeve. Results of this second set of procedural blanks yielded a mean

222 value of $(1.84 \pm 0.38) \times 10^{5}{ }^{14} \mathrm{C}$ atoms $(\mathrm{n}=3)$, indistinguishable from the previous mean value

223 but with a slightly lower COV of $20.4 \%$ (Fig. 4). Reasoning that the He procedure did not appear

224 detrimental to the results, and given the potential for limiting atmospheric $\mathrm{C}$ contamination in the

225 extraction systems with this method, we continued to use the He procedure going forward. A

226 third set of process blanks for Line 2 with this procedure yielded a somewhat higher mean blank

227 value of $(2.27 \pm 0.06) \times 10^{5}{ }^{14} \mathrm{C}$ atoms, but with excellent reproducibility $(\mathrm{COV}=2.7 \%)($ Fig. 4).

228 Identical procedures were used on both systems, leaving the source(s) of the differences between

229 the two systems unclear. Overall backgrounds for the two extraction systems are similar to

230 previous systems $[1,2,9,17]$.

$231 \quad \underline{3.3-\text { CRONUS-A analyses }}$

232 Intercomparison materials generated as part of the Cosmic-Ray Produced Nuclide

233 Systematics on Earth (CRONUS) project were used to compare extraction system yields with

234 previous results from in $\operatorname{situ}{ }^{14} \mathrm{C}$ labs at Arizona, Lamont-Doherty Earth Observatory, and ETH-

235 Zurich [12] (Table 3, Fig. 5). Initial tests used the standard $5 \mathrm{~g}$ of quartz used in those procedures

$236[1,2,9,17]$, both with and without He flushing. Results with and without He are

237 indistinguishable from those presented in Jull et al. [12]. We then explored the possibility of

238 using larger sample sizes to allow increased AMS ratios, to yield results farther above

239 background levels than possible with $5 \mathrm{~g}$ samples $\left(4: 1 \mathrm{LiBO}_{2}\right.$ :quartz). Both $10 \mathrm{~g}(2: 1$

$240 \quad \mathrm{LiBO}_{2}$ :quartz) and $20 \mathrm{~g}\left(1: 1 \mathrm{LiBO}_{2}\right.$ :quartz) sample sizes were attempted. $10 \mathrm{~g}$ sample sizes

241 yielded results that were indistinguishable from those using $5 \mathrm{~g}$, but the $20 \mathrm{~g}$ analysis was 
242 significantly lower (Fig. 5). This suggests that $10 \mathrm{~g}$ sample sizes allow full recovery of in

243 situ ${ }^{14} \mathrm{C}$, while $20 \mathrm{~g}$ results in incomplete recovery. The $20 \mathrm{~g}$ result is likely due to the higher

244 viscosity of the melt with the lower $\mathrm{LiBO}_{2}$ :quartz ratio, leading to slower dissolution and/or $\mathrm{CO}_{2}$

245 degassing rates. In theory, longer extractions at the $1: 1$ ratio could extract the in situ ${ }^{14} \mathrm{C}$ fully, but

246 our extraction times are limited by the corrosiveness of the $\mathrm{LiBO}_{2}$ vapor - longer times typically

247 lead to structural failure of our $\mathrm{Al}_{2} \mathrm{O}_{3}$ sample boats and/or the quartz sleeve that shields the

248 furnace tube from the vapor. The mean of 5 and $10 \mathrm{~g}$ samples is $(6.89 \pm 0.04) \times 10^{5}{ }^{14} \mathrm{C}$ atoms $/ \mathrm{g}$

$249(\mathrm{n}=6, \mathrm{COV} 0.6 \%)$, compared to $(6.93 \pm 0.44) \times 10^{5}{ }^{14} \mathrm{C}$ atoms/g $(\mathrm{n}=23, \mathrm{COV} 6.3 \%)$ in Jull et

250 al. [12], demonstrating the increased reproducibility of our automated systems, as well as the

251 efficacy of our purification procedures with only 2 VTTs. 5-10 g sample sizes are now in routine 252 use in our lab.

\section{$253 \quad 4.0$-Conclusions}

254 Initial operation of the PRIME Lab in situ ${ }^{14} \mathrm{C}$ laboratory indicates that much of the promise 255 of automation has been achieved. Automating the extraction and purification procedures has

256 enabled increased sample throughput and improved reproducibility, as evidenced by faster

257 procedures and highly reproducible CRONUS-A analyses on quartz sample masses up to $10 \mathrm{~g}$.

258 Procedural blank levels can still be improved, but early results are comparable to previous work

259 on previous manually operated systems. Improving the blank and improving overall system

260 reliability is a priority for ongoing work. Based on these initial results, we are now measuring 261 unknowns routinely. 


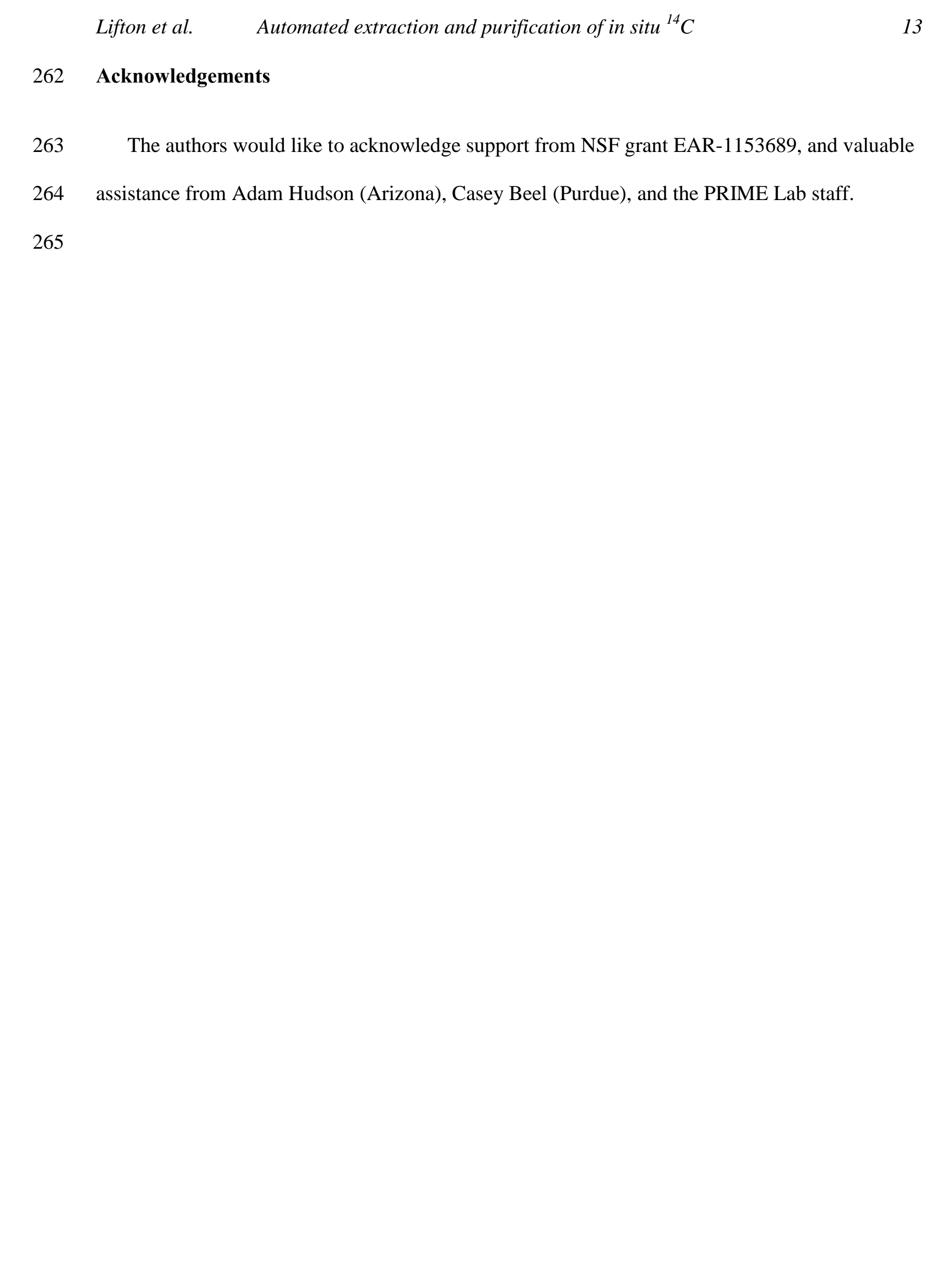


Lifton et al. $\quad$ Automated extraction and purification of in situ ${ }^{14} \mathrm{C}$

266

267 1. Lifton, N., A. Jull, and J. Quade, A new extraction technique and production rate estimate 268 269

270

271

272

273

274

275

276

277

278

279

280

28

282

283

284

285 for in situ cosmogenic ${ }^{14} \mathrm{C}$ in quartz. Geochimica Et Cosmochimica Acta, 2001. 65(12): p. 1953-1969.

2. Pigati, J., N. Lifton, A. Jull, and J. Quade, A simplified in situ cosmogenic ${ }^{14} \mathrm{C}$ extraction system. Radiocarbon, 2010. 52(2-3): p. 1236-1243.

3. Hippe, K., F. Kober, L. Wacker, S. Fahrni, S. Ivy-Ochs, N. Akcar, C. Schluchter, and R. Wieler, An update on cosmogenic in situ ${ }^{14} \mathrm{C}$ analysis at Zürich. Nuclear Instruments and Methods B, 2013: p. 1-19.

4. Jull, A., D. Donahue, and T. Linick, Carbon-14 activities in recently fallen meteorites and Antarctic meteorites. Geochimica Et Cosmochimica Acta, 1989. 53: p. 2095-2100.

5. Jull, A., D. Donahue, T. Linick, and G. Wilson, Spallogenic ${ }^{14} \mathrm{C}$ in high-altitude rocks and in Antarctic meteorites. Radiocarbon, 1989. 31(3): p. 719-724.

6. des Marais, D., Light element geochemistry and spallogenesis in lunar rocks. Geochimica Et Cosmochimica Acta, 1983. 47: p. 1769-1781.

7. Des Marais, D.J. and J.G. Moore, Carbon and its isotopes in mid-oceanic basaltic glasses. Earth and Planetary Science Letters, 1984. 69: p. 43-57.

8. Hippe, K., F. Kober, H. Baur, M. Ruff, L. Wacker, and R. Wieler, The current performance of the in situ ${ }^{14} \mathrm{C}$ extraction line at ETH. Quaternary Geochronology, 2009. 4(6): p. 493-500. 
Lifton et al. $\quad$ Automated extraction and purification of in situ ${ }^{14} \mathrm{C}$

2869 9. Goehring, B.M., I. Schimmelpfennig, and J.M. Schaefer, Capabilities of the

287 Lamont-Doherty Earth Observatory in situ ${ }^{14} \mathrm{C}$ extraction laboratory updated. Quaternary 288 Geochronology, 2013: p. 1-18.

289 10. Santos, G., J. Southon, K. Druffel-Rodriguez, S. Griffin, and M. Mazon, Magnesium 290 Perchlorate as an Alternative Water Trap in AMS Graphite Sample Preparation: A Report 291 on Sample Preparation at KCCAMS at the University of California, Irvine. Radiocarbon, 292 2004. 46(1): p. 165-174.

293 11. Santos, G., M. Mazon, J. Southon, S. Rifai, and R. Moore, Evaluation of iron and cobalt 294 powders as catalysts for ${ }^{14} \mathrm{C}$-AMS target preparation. Nuclear Instruments and Methods in 295 Physics Research Section B: Beam Interactions with Materials and Atoms, 2007. 259(1): 296 p. 308-315.

297 12. Jull, A.J.T., E.M. Scott, and P. Bierman, The CRONUS-Earth inter-comparison for 298 cosmogenic isotope analysis. Quaternary Geochronology, 2013: p. 1-8.

299 13. Hippe, K. and N.A. Lifton, Calculating isotope ratios and nuclide concentrations for in 300 situ cosmogenic ${ }^{14} \mathrm{C}$ analyses. Radiocarbon, 2014. 56(3): p. 1167-1174.

301 14. Slota, P., A. Jull, T. Linick, and L. Toolin, Preparation of small samples for ${ }^{14} \mathrm{C}$ 302 accelerator targets by catalytic reduction of CO. Radiocarbon, 1987. 29(2): p. 303-306.

303 15. Donahue, D., A. Jull, and L. Toolin, Radiocarbon measurements at the University of 304 Arizona AMS facility. Nuclear Instruments and Methods in Physics Research B, 1990. $305 \quad$ 52: p. 224-228. 
Lifton et al. $\quad$ Automated extraction and purification of in situ ${ }^{14} \mathrm{C}$

306 16. Santos, G., J. Southon, S. Griffin, S. Beaupre, and E. Druffel, Ultra small-mass

307 AMS ${ }^{14} \mathrm{C}$ sample preparation and analyses at KCCAMS/UCI Facility. Nuclear Inst. and 308 Methods in Physics Research, B, 2007. 259(1): p. 293-302.

309 17. Miller, G., J. Briner, N. Lifton, and R.C. Finkel, Limited ice-sheet erosion and complex 310 exposure histories derived from in situ cosmogenic ${ }^{10} \mathrm{Be},{ }^{26} \mathrm{Al}$, and ${ }^{14} \mathrm{C}$ on Baffin Island, 311 Arctic Canada. Quaternary Geochronology, 2006. 1(1): p. 74-85. 
Lifton et al. $\quad$ Automated extraction and purification of in situ ${ }^{14} \mathrm{C}$

\section{List of Figures}

314 Fig. 1: Schematic of PRIME Lab in situ ${ }^{14} \mathrm{C}$ extraction systems. $\mathrm{Al}_{2} \mathrm{O}_{3}$ sample boat is placed

Fig. 2: A) PRIME Lab in situ ${ }^{14} \mathrm{C}$ extraction (left side of lab frame) and purification (right side of frame) systems. B) PRIME Lab ${ }^{14} \mathrm{C}$ graphitization reactors. C) Control electronics for the purification system. Extraction systems have similar enclosures. D) Valve actuator assembly for glass valves, with guide rods and limit switch circuitry. E) Valve actuator assembly for SS-4BK valves, with bracket for circuitry. Valve travel between open and closed positions is too small for limit switches. Instead, a prescribed time interval is used for opening and a current limit associated with increased torque at closure stops the actuator.

Fig. 3: Plot showing mass dependence of graphitization systems, with best-fit equation.

Fig. 4: Process blanks from both extraction systems. System 1 blanks include runs with and without positive pressure He backfilling the furnace tube during tube opening. System 2 blanks only include He backfilling procedures. Mean and standard deviation indicated for each set of samples. 
334 Fig. 5: Results for CRONUS-A intercomparison material, for different masses of quartz

335 as indicated. 5-10 g of quartz give indistinguishable results which are also

336 indistinguishable from results presented by Jull et al. [12], while $20 \mathrm{~g}$ has a significantly

$337 \quad$ lower yield indicating incomplete recovery. 
Lifton et al. Automated extraction and purification of in situ ${ }^{14} \mathrm{C}$

1 Table 1 - Mass dependence of graphitization blank

\begin{tabular}{|c|c|c|c|}
\hline $\begin{array}{l}\text { Sample } \\
\text { Number }\end{array}$ & $\begin{array}{c}\text { Mass C } \\
m g\end{array}$ & $\begin{array}{c}{ }^{{ }^{14}} \mathbf{C} /{ }^{13} \mathbf{C} \\
10^{-13} \\
\end{array}$ & $\begin{array}{c}{ }^{14} \mathbf{C} / \mathbf{C}_{\text {total }} \\
10^{-15} \\
\end{array}$ \\
\hline PISC-57 & 0.401 & $2.863 \pm 0.440$ & $3.013 \pm 0.463$ \\
\hline PISC-58 & 0.644 & $2.597 \pm 0.206$ & $2.733 \pm 0.217$ \\
\hline PISC-59 & 1.137 & $1.978 \pm 0.189$ & $2.082 \pm 0.199$ \\
\hline PISC-60 & 2.030 & $2.449 \pm 0.180$ & $2.577 \pm 0.190$ \\
\hline PISC-61 & 0.413 & $2.841 \pm 0.490$ & $2.990 \pm 0.516$ \\
\hline PISC-62 & 0.141 & $3.911 \pm 0.858$ & $4.116 \pm 0.903$ \\
\hline PISC-63 & 0.210 & $3.299 \pm 0.011$ & $3.472 \pm 1.109$ \\
\hline PISC-64 & 0.312 & $3.364 \pm 0.558$ & $3.540 \pm 0.587$ \\
\hline
\end{tabular}

2 Note: $\delta^{13} \mathrm{C}=-46.1 \%$ 
Table 2 - Extraction system blanks

\begin{tabular}{|c|c|c|c|c|c|c|c|}
\hline $\begin{array}{l}\text { Sample } \\
\text { Number }\end{array}$ & $\begin{array}{c}\mathbf{C O}_{2} \text { Yield } \\
10^{-2} \mathrm{~mL}\end{array}$ & $\begin{array}{c}\text { Diluted } \mathbf{C O}_{2} \\
10^{-1} \mathrm{~mL}\end{array}$ & $\begin{array}{c}\text { AMS COO } \mathbf{C p l i t} \\
110^{-1} \mathrm{~mL}\end{array}$ & $\begin{array}{c}{ }^{{ }^{14}} \mathbf{C} /{ }^{13} \mathbf{C} \\
10^{-12}\end{array}$ & $\begin{array}{c}\delta^{\mathbf{1 3}} \mathbf{C} \\
\% o\end{array}$ & $\begin{array}{c}{ }^{14} \mathbf{C} / \mathbf{C}_{\text {total }} \\
10^{-14}\end{array}$ & $\begin{array}{c}{ }^{14} \mathbf{C} \\
10^{5} \text { at }\end{array}$ \\
\hline PISC-15 & $3.585 \pm 0.220$ & $7.786 \pm 0.080$ & $7.070 \pm 0.074$ & $1.087 \pm 0.044$ & -45.7 & $0.900 \pm 0.072$ & $1.882 \pm 0.150$ \\
\hline PISC-18 & $3.364 \pm 0.220$ & $7.699 \pm 0.080$ & $6.960 \pm 0.073$ & $1.202 \pm 0.077$ & -45.9 & $1.021 \pm 0.098$ & $2.111 \pm 0.202$ \\
\hline PISC-24 & $2.668 \pm 0.222$ & $7.723 \pm 0.080$ & $6.992 \pm 0.073$ & $0.922 \pm 0.041$ & -44.5 & $0.788 \pm 0.047$ & $1.389 \pm 0.098$ \\
\hline PISC-28 & $2.509 \pm 0.222$ & $7.776 \pm 0.080$ & $7.061 \pm 0.074$ & $8.960 \pm 0.037$ & -45.6 & $7.590 \pm 0.044$ & $1.341 \pm 0.092$ \\
\hline PISC-31 & $3.904 \pm 0.222$ & $7.897 \pm 0.082$ & $7.152 \pm 0.074$ & $1.198 \pm 0.043$ & -45.6 & $1.077 \pm 0.050$ & $2.038 \pm 0.105$ \\
\hline PISC-33 & $3.281 \pm 0.221$ & $8.269 \pm 0.085$ & $7.482 \pm 0.775$ & $1.081 \pm 0.047$ & -46.3 & $0.953 \pm 0.054$ & $1.865 \pm 0.119$ \\
\hline \multirow[t]{2}{*}{ PISC-35 } & $1.593 \pm 0.220$ & $18.20 \pm 0.182$ & $16.52 \pm 0.166$ & $0.421 \pm 0.012$ & -48.2 & $0.258 \pm 0.024$ & $0.878 \pm 0.106$ \\
\hline & & & & & & Mean & $1.643 \pm 0.451$ \\
\hline PISC- $36^{\mathrm{a}}$ & $2.879 \pm 0.221$ & $7.389 \pm 0.0767$ & $6.699 \pm 0.0701$ & $0.976 \pm 0.023$ & -45.5 & $0.843 \pm 0.031$ & $1.434 \pm 0.062$ \\
\hline PISC-41 ${ }^{\mathrm{a}}$ & $2.872 \pm 0.223$ & $7.785 \pm 0.0806$ & $7.045 \pm 0.074$ & $1.155 \pm 0.022$ & -46.0 & $1.031 \pm 0.031$ & $1.911 \pm 0.064$ \\
\hline \multirow[t]{2}{*}{ PISC-42 ${ }^{\mathrm{a}}$} & $2.751 \pm 0.222$ & $7.763 \pm 0.080$ & $7.216 \pm 0.075$ & $1.276 \pm 0.036$ & -46.1 & $1.158 \pm 0.043$ & $2.174 \pm 0.090$ \\
\hline & & & & & & Mean & $1.839 \pm 0.375$ \\
\hline PISC-47 $7^{\mathrm{a}, \mathrm{b}}$ & $2.273 \pm 0.220$ & $7.622 \pm 0.079$ & $6.896 \pm 0.072$ & $1.301 \pm 0.053$ & -46.6 & $1.184 \pm 0.059$ & $2.180 \pm 0.122$ \\
\hline PISC-49 $9^{\mathrm{a}, \mathrm{b}}$ & $2.495 \pm 0.220$ & $7.566 \pm 0.078$ & $6.804 \pm 0.071$ & $1.365 \pm 0.061$ & -46.3 & $1.252 \pm 0.068$ & $2.300 \pm 0.138$ \\
\hline PISC-53 ${ }^{a, b}$ & $2.448 \pm 0.223$ & $7.543 \pm 0.078$ & $6.825 \pm 0.071$ & $1.352 \pm 0.052$ & -46.4 & $1.238 \pm 0.058$ & $2.266 \pm 0.117$ \\
\hline \multirow[t]{2}{*}{ PISC-55 $5^{\mathrm{a}, \mathrm{b}}$} & $2.299 \pm 0.219$ & $7.655 \pm 0.079$ & $6.861 \pm 0.072$ & $1.361 \pm 0.054$ & -46.3 & $1.247 \pm 0.061$ & $2.320 \pm 0.125$ \\
\hline & & & & & & Mean & $2.267 \pm 0.062$ \\
\hline
\end{tabular}

2 Notes: All analyses done on Extraction system 1 except as indicated.

3 a Backflow with He slightly above atmospheric pressure during furnace tube opening

4 b Extraction Line 2 
2 Table 3 - CRONUS-A analytical results

\begin{tabular}{|c|c|c|c|c|c|c|c|c|}
\hline $\begin{array}{l}\text { Sample } \\
\text { Number }\end{array}$ & $\begin{array}{c}\text { Mass } \\
\text { quartz } \\
g \\
\end{array}$ & $\begin{array}{c}\mathrm{CO}_{2} \text { Yield } \\
10^{-1} \mathrm{~mL} \\
\end{array}$ & $\begin{array}{c}\text { Diluted } \mathbf{C O}_{2} \\
10^{-1} \mathrm{~mL} \\
\end{array}$ & $\begin{array}{c}\text { AMS CO}_{2} \\
\text { Split } \\
10^{-1} \mathrm{~mL} \\
\end{array}$ & $\begin{array}{c}{ }^{1 \mathbf{1 4}} \mathbf{C} /{ }^{\mathbf{1 3}} \mathbf{C} \\
10^{-11}\end{array}$ & $\begin{array}{c}\boldsymbol{\delta}^{13} \mathbf{C} \\
\% o\end{array}$ & $\begin{array}{c}{ }^{{ }^{14}} \mathbf{C} / \mathbf{C}_{\text {total }} \\
10^{-13}\end{array}$ & $\begin{array}{c}{\left[{ }^{\mathbf{1 4}} \mathbf{C}\right]} \\
10^{5} \text { at } g^{-1}\end{array}$ \\
\hline PISC-16 & 5.023 & $0.758 \pm 0.023$ & $8.013 \pm 0.083$ & $7.301 \pm 0.076$ & $1.659 \pm 0.032$ & -43.9 & $1.720 \pm 0.033$ & $7.042 \pm 0.185$ \\
\hline PISC-17 & 5.008 & $0.797 \pm 0.023$ & $7.992 \pm 0.082$ & $7.218 \pm 0.075$ & $1.633 \pm 0.026$ & -44.0 & $1.692 \pm 0.028$ & $6.924 \pm 0.166$ \\
\hline PISC-30 & 10.031 & $1.318 \pm 0.025$ & $8.754 \pm 0.090$ & $7.980 \pm 0.082$ & $2.877 \pm 0.029$ & -41.6 & $3.013 \pm 0.031$ & $6.895 \pm 0.112$ \\
\hline PISC-32 & 20.058 & $2.196 \pm 0.031$ & $10.480 \pm 0.107$ & $9.444 \pm 0.096$ & $4.159 \pm 0.048$ & -40.0 & $4.376 \pm 0.051$ & $6.058 \pm 0.097$ \\
\hline PISC- $37^{\mathrm{a}}$ & 5.030 & $0.768 \pm 0.023$ & $8.424 \pm 0.087$ & $7.818 \pm 0.081$ & $1.544 \pm 0.036$ & -43.5 & $1.600 \pm 0.038$ & $6.829 \pm 0.208$ \\
\hline PISC-38 ${ }^{\text {a }}$ & 10.001 & $1.217 \pm 0.025$ & $8.645 \pm 0.089$ & $8.021 \pm 0.083$ & $2.911 \pm 0.030$ & -41.7 & $3.048 \pm 0.032$ & $6.891 \pm 0.113$ \\
\hline PISC-39 ${ }^{a}$ & 10.004 & $1.207 \pm 0.025$ & $8.661 \pm 0.089$ & $8.031 \pm 0.083$ & $2.842 \pm 0.029$ & -42.0 & $2.974 \pm 0.031$ & $6.730 \pm 0.111$ \\
\hline & & & & & & \multicolumn{2}{|c|}{ Mean (no PISC-32) } & $6.885 \pm 0.043$ \\
\hline
\end{tabular}

3 Notes: Uncertainty in quartz mass $= \pm 0.2 \mathrm{mg}$

4 a Backflow with He slightly above atmospheric pressure during furnace tube opening 
$1200^{\circ} \mathrm{C}$-capable resistance furnace with mullite furnace tube

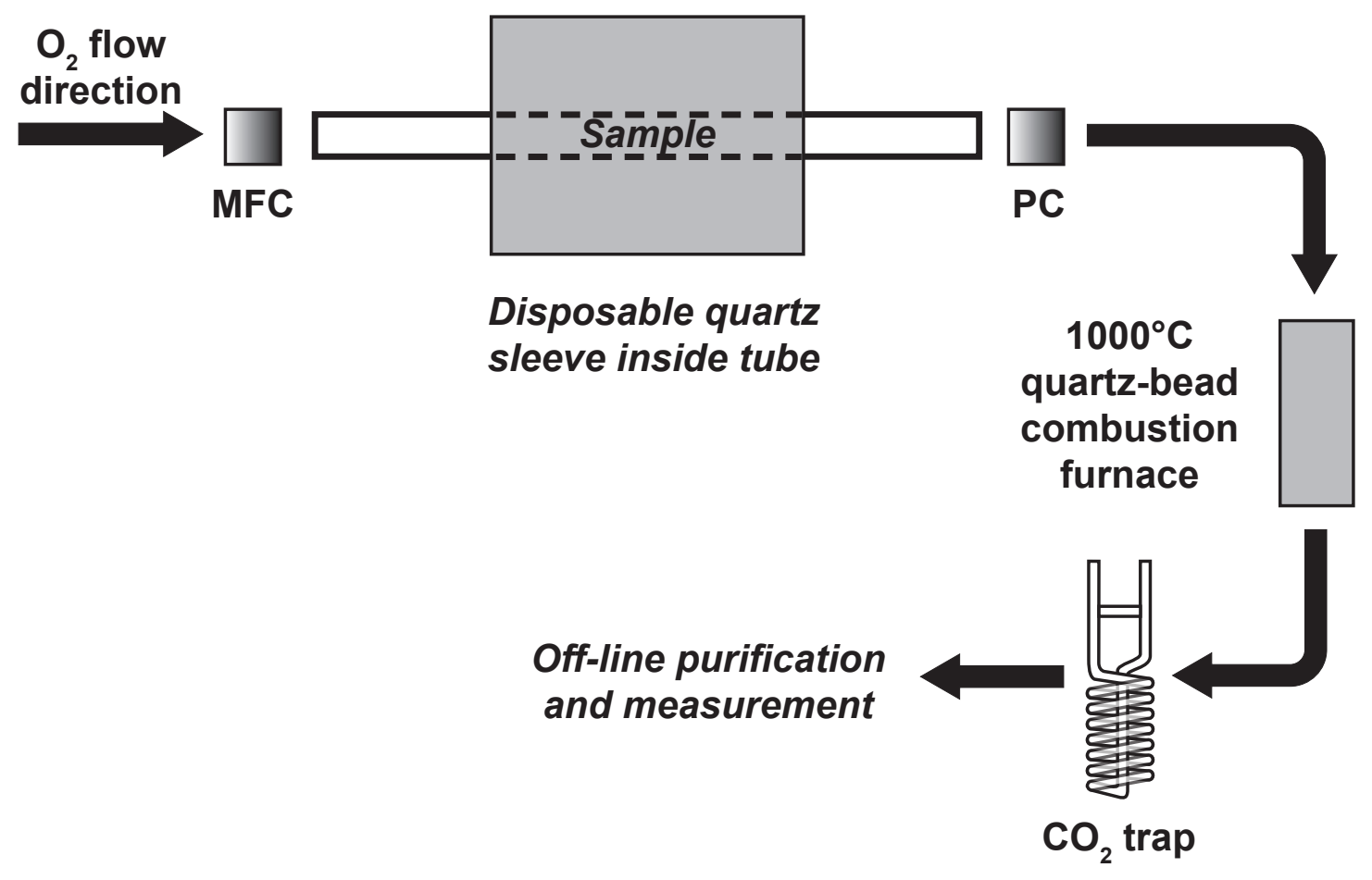



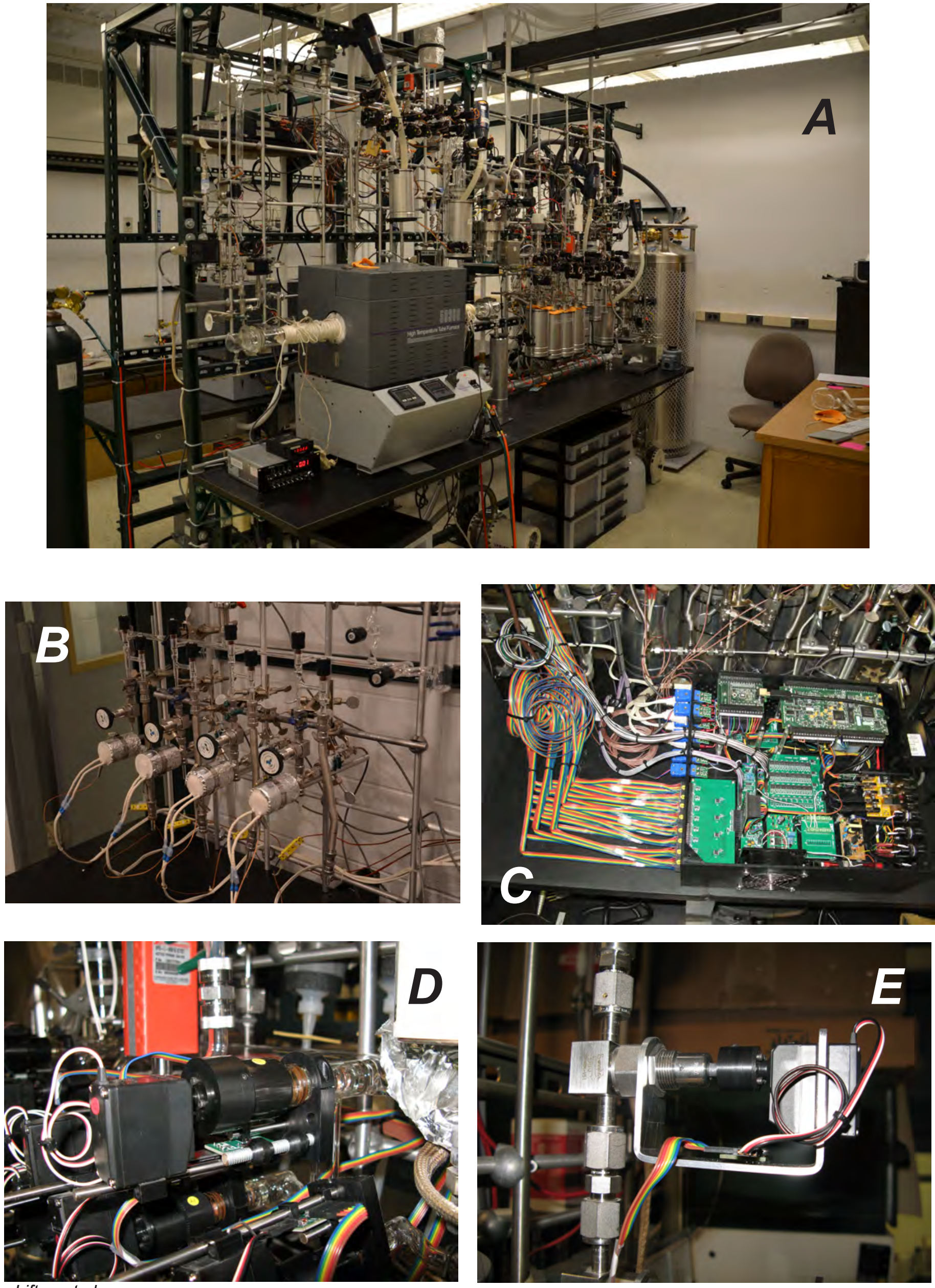

Lifton et al.

Progress in automated extraction and purification of in situ ${ }^{14} \mathrm{C}$ from quartz

Fig. 2 


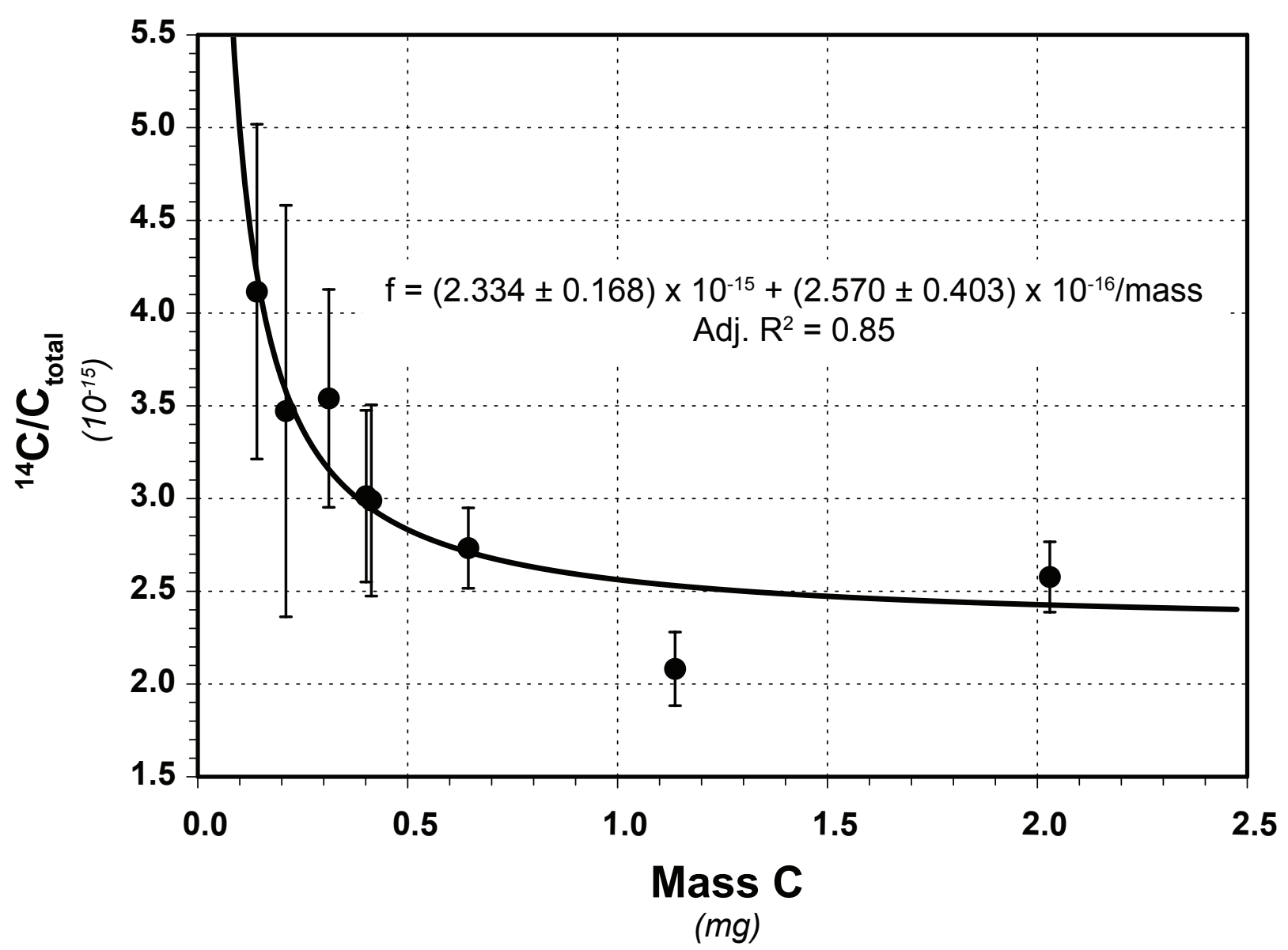




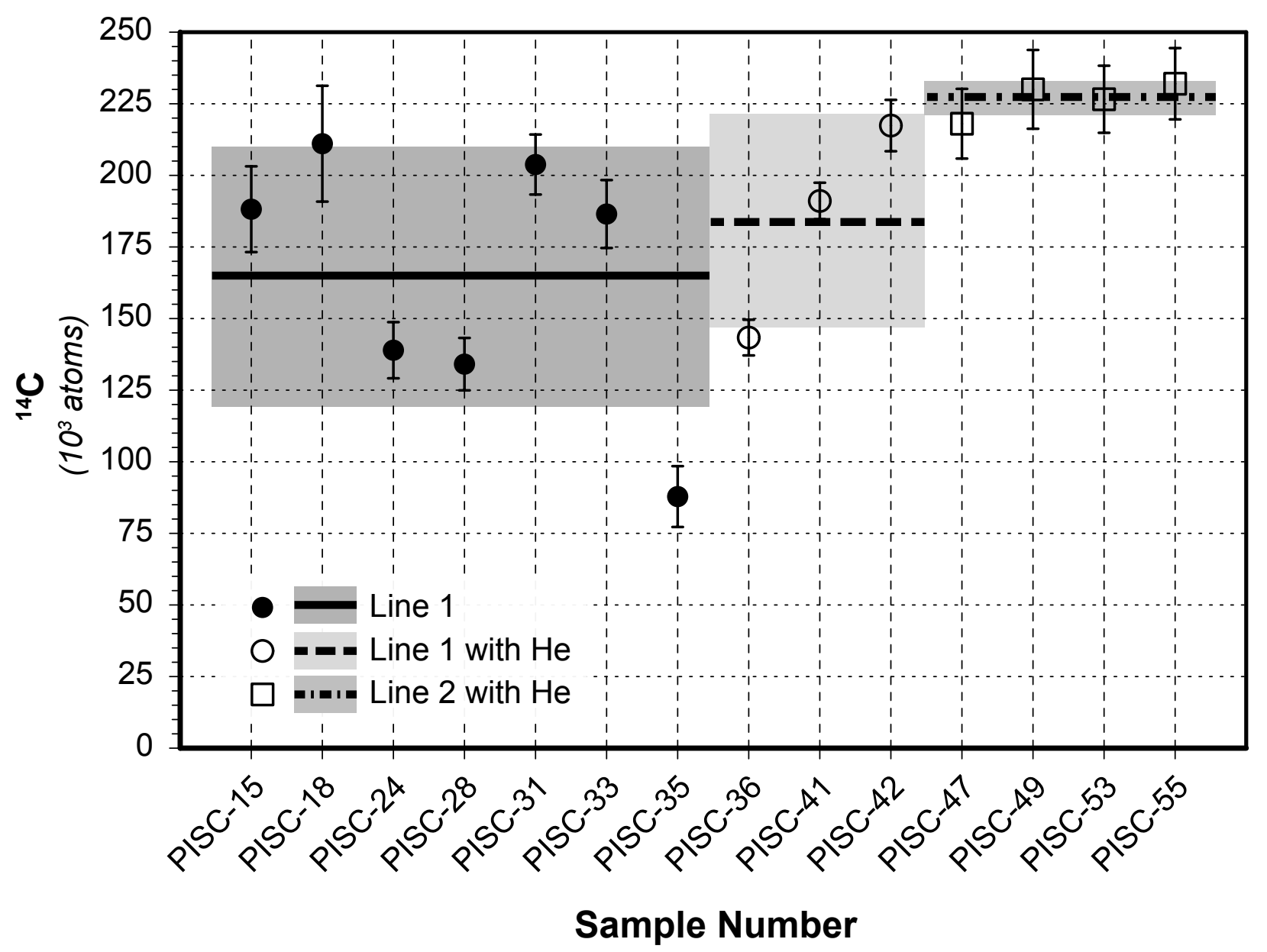

Lifton et al.

Progress in automated extraction and purification of in situ ${ }^{14} \mathrm{C}$ from quartz 


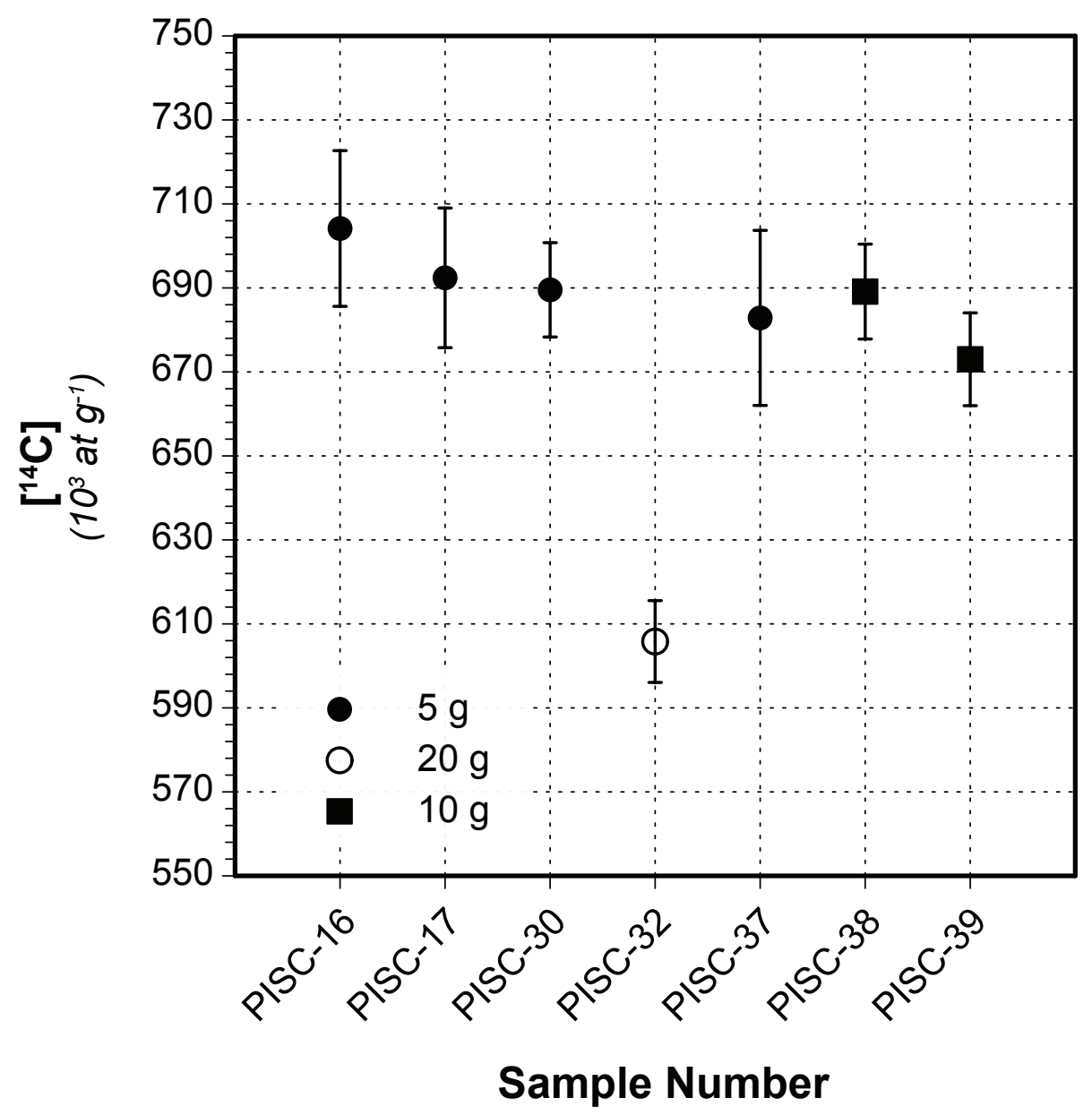

